Revue d'histoire de l'Amérique française

REVUE D.HISTOIRE DE L'AMÉRIQUE FRANÇAISE

\title{
Les Français de l'Illinois de 1778 à 1792
}

\section{Agnès Dureau}

Volume 1, numéro 4, mars 1948

URI : https://id.erudit.org/iderudit/801410ar

DOI : https://doi.org/10.7202/801410ar

Aller au sommaire du numéro

Éditeur(s)

Institut d'histoire de l'Amérique française

ISSN

0035-2357 (imprimé)

1492-1383 (numérique)

Découvrir la revue

Citer cet article

Dureau, A. (1948). Les Français de l'Illinois de 1778 à 1792. Revue d'histoire de l'Amérique française, 1(4), 495-500. https://doi.org/10.7202/801410ar d'utilisation que vous pouvez consulter en ligne.

https://apropos.erudit.org/fr/usagers/politique-dutilisation/ 


\section{LES FRANÇAIS DE L'ILLINOIS DE 1778 A 1792}

Les Français n'ont pas la tête épique, disait Voltaire, qui se vengeait ainsi du peu de succès de sa Henriade. A plus juste titre eât-il pu reprocher aux Français de son temps en général et à lui-même en particulier de n'avoir pas l'esprit colonial.

Quand on songe à l'immense empire que la France aurait pu avoir, à celui déjà si vaste qu'elle possédait au temps de Louis XV, on ne peut s'empêcher d'être péniblement frappé de la criminelle indifférence avec laquelle le gouvernement laissa presque à l'abandon ses colonies et s'en vit enlever la plus grande partie par le désastreux traité de 1763. Et pourtant, rien que dans l'Amérique du Nord, nous perdions d'immenses territoires: le Canada, la Louisiane et le pays des Illinois, beaucoup plus petit il est vrai, mais fort important toutefois, parce qu'il servait de trait d'union entre les deux autres colonies.

Les postes de l'Illinois tiraient leur origine de missions chrétiennes. Marquette y prêcha l'évangile et établit en $1673 \mathrm{chez}$ les Indiens Kaskaskias une mission près de la ville actuelle d'Utica (Illinois), puis, cinq ans plus tard, le jésuite Claude Allouez vint fonder dans le gros village où se groupait alors toute la peuplade illinoise (refoulée par les Iroquois au-delà du Mississipi) la mission de l'Immaculée Conception qui devait être le premier établissement européen dans le bassin du Mssissipi. ${ }^{1}$

En 1680 La Salle éleva sur l'Illinois, et à deux ljeues de son embouchure, le fort St. Louis autour duquel il accorda des terres à plusieurs de ses Canadiens ${ }^{2}$ et le 9 avril 1682 il prit formellement possession de toute la région au nom de son maitre le roi de France Louis XIV, et lui donna le nom de Louisiane; bientôt des jésuites y arrivèrent et $\mathrm{y}$ organisèrent des missions où vinrent s'établir des " coureurs de

1. Bancroft, History of the United States, 11, p. 360.

2. Heinrich, La Louisiane sous la compagnie des Indes, p. 22. 
bois n, hardis Français attirés par l'aventure ou par le désir d'exploiter les mines qu'on avait, disait-on, découvertes dans ces parages.

Ce fut bientôt une colonie qui promettait de devenir prospère. Situee dans ce qu'on appelait alors " the American Bottom ", sur les rives du Mississipi, depuis le confluent du Missouri et jusqu'à celui du . Kaskaskia, elle embrassait le centre et le sud de l'état actuel d'Illinois et une partie du nord-ouest de l'Indiana. A l'opposé des " frontiersmen " américains qui vivaient plutôt isolés les uns des autres, les Français étaient groupés par villages, toujours pourvus d'un champ communal où paissaient les troupeaux. Le blé poussait en abondance sur un sol fertile; la vie toute patriarcale ne différait pas sensiblement de celle qu'on menait alors en France et, dans l'ensemble, des relations cordiales existaient avec les Indiens.

Le traité de 1763 porta un coup terrible à la petite colonie. L'Anglais était l'ennemi héréditaire; plutôt que de passer sous sa domination détestée, beaucoup de colons préférèrent traverser le Mississipi et aller s'établir dans la partie cédée à l'Espagne où ils retrouvaient tout au moins une race et une civilization similaires aux leurs, si bien que lorsque le recensement de 1768 fut fait il ne restait plus que 1,358 Français dans les cinq villages de Kaskaskia (au sud), Cahokia (au nord), Prairie du Rocher, Chartres et St. Philippe (au centre), plus 427 a Vincennes et 126 à Ouatanou, deux établissements sur le Wabash, et 90 au poste de St. Joseph au nord-est du lac Michigan. ${ }^{3}$

Tout d'abord le pays des Illinois fut laissé plus ou moins à l'abandon, puis, par l'acte de Québec de 1774, on le joignit au Canada, mais pour bien peu de temps. Un jeune officier du Kentucky, George Rogers Clark, avait eu en effet une idée géniale. Tandis que la guerre se déroulait dans l'est, pourquoi n'essaierait-il pas d'attaquer les Anglais du côté de l'ouest et de prendre Détroit qui lui ouvrirait les portes du Canada? Mais pour réussir il lui fallait d'abord s'assurer des postes de l'Illinois; or Clark n'ignorait pas d'une part que les soldats anglais qui s'y trouvaient au début de la guerre, avaient été transférés plus au nord, de l'autre, que les Français qui y habitaient n'étaient pas attachés à la cause anglaise et qu'il ne suffirait que d'un peu d'habileté pour les convaincre d'ajder les Américains. ${ }^{4}$

3. TAsse, Les Canadiens de l'Ouest, (Dans MagnaN, Histoire de la race française aux Etats-Unis, p. 160).

4. Clark \& Patrick Henry, Illinois Historical Collections, Vol. VIII. p. 30-32. 
Clark sut gagner à ses vues le gouverneur de Virginie, Patrick Henry ${ }^{5}$ et, pourvu du titre de lieutenant-colonel, obtint l'autorisation de lever une milice de 350 hommes et de faire une expédition dans l'Illinois. Au début de juillet 1778 il entre à Kaskaskia sans coup férir et adresse aux habitants des paroles enflammées: "Le roi de France vient de joindre ses armes puissantes à celles de l'Amérique et la guerre sera bientôt finie. ${ }^{6}$ Vous êtes libres de vous joindre à nous si vous le désirez. Allez et dites à vos compatriotes que, aussi longtemps que nous serons les maîtres ici, ils ne seront molestés en aucune façon, qu'ils auront toute liberté de pratiquer leur religion et qu'ils peuvent faire ce qu'il leur plaît. ") "

Électrisés par ces paroles, les Kaskaskians se soumettent immédiatement et leur exemple est suivi par Cahokia le lendemain et Vincennes quelques jours plus tard, le 19 juillet. Dans la capture de ce poste Clark fut puissamment aidé par deux Français, le docteur Lafont et l'abbé Gibault, alors vicaire-général de l'évêque de Québec dans l'Illinois, qui portèrent aux habitants une déclaration signée de Clark qui les invitait à embrasser la cause de la rébellion, ${ }^{8}$ ce qu'ils firent avec enthousiasme. Non seulement les Français fournirent aux Américains les armes, les munitions et les vivres dont ils avaient un pressant besoin, mais nombreux furent ceux qui s'enrôlèrent dans la troupe de Clark qui, rien que dans les deux villages de Kaskaskia et Cahokia, put lever deux compagnies.

Six mois plus tard, le gouverneur anglais, Henry Hamilton, essayera de reprendre les postes conquis par les Américains; il réussira d'abord à Vincennes; mais Clark, aidé par les volontaires français, se saisit de nouveau de la place, le 23 février 1779, ce qui lui assura définitivement la maîtrise de l'ouest, comme il l'atteste dans une lettre a Thomas Nelson du premier octobre 1781: "Il n'y a pas l'ombre d'un doute que depuis le commencement de la guerre nos possessions de l'Illinois et du Kentucky ont été la sauvegarde de toutes nos frontières intérieures. " $" 9$

5. I.H.C. Vol. VIII. p. 34-35.

6. Traités des 6 et 8 février 1778.

7. John Monetre, La Vallée du Mississipi, (Dans MAGN AN, ouvrage cité, p. 176).

8. I.H.C. Vol. VIII. p. 50-54.

9. I.H.C. Vol. VIII. p. 605-608. 
La Virginie organise alors le pays conquis, tout d'abord elle crée le comté d'Illinois, le 9 décembre 1778, lequel embrasse toute la région occupée par Clark de "l'Ohio à l'Illinois et en remontant le Wabash vers Détroit jusqu'à une limite indéfinie ", ${ }^{10}$ puis Clark établit à Kaskaskia, Cahokia et Vincennes, des "courts ) ou tribunaux civils modelés sur ceux des comtés virginiens, mais composés de magistrats français: six " justices " ou juges de paix, élus dans le principal village et représentant les autres localités du district. ${ }^{11}$ On doit juger suivant la " coutume de Paris" mais modifiée quelque peu par les lois de Virginie. ${ }^{12}$ De plus, Clark se réserve à lui-même le droit d'appel.

Les archives des " courts " de Kaskaskia et de Cahokia retrouvées en 1904 par Mr. Alvord et patiemment recueillies, classées et publiées, sont extrêmement curieuses et présentent un tableau fidèle de la vie de la petite colonje française à cette époque-là. Rédigés dans un français fantaisiste et qui ignore souvent les règles de l'orthographe et de la ponctuation, émaillés de majuscules mises à tout propos et le plus souvent hors de propos, ces documents sont d'une piquante saveur.

Mais là ne se borne pas leur intérêt; ils nous montrent aussi les rapports parfois tendus qui existaient entre les Virginiens et les Français dont la bonne volonté attestée par Clark, Patrick Henry lui-même ${ }^{13}$, est bientôt mise à une rude épreuve. Les Virginiens manquent de tout et ils trouvent tout naturel de s'approvisionner chez leurs alliés, malgré les louables efforts de John Todd, ami de Clark, nommé " county-lieutenant " en 1778 et qui essaie de protéger ses administrés contre les exactions de ses compatriotes. Dans leur infortune les habitants se plaignent à tout le monde, d'abord à Clark ${ }^{14}$ et à leurs magistrats, puis au gouvernement de Virginie ${ }^{15}$, enfin au colonel de la Balme, envoyé du roi de France, auquel ils adressent le 21 septembre 1780 une pétition dans laquelle ils expriment leur

10. I.H.C. Vol. II. Introduction. p. 52.

11. Le district de Kaskaskia comprenait outre le village de ce nom, Prairie du Rocher, Chartres et St. Philippe; celui de Cahokia s'étendait de Prairie du Pont a Peoria; et Vincennes renfermait toute la région du Wabash.

12. I.H.C. Vol. II. Intro. p. 63.

13. 16 nov. 1778. I.H.C. Vol. VIII. p. 72-74.

14. Avril 1780. I.H.C. Vol. II. p. 530-537.

15. 30 juin 1781. I.H.C. Vol. VIII. p. $430-433$. 
attachement inébranlable au nom de Français, pour lequel, disentils, "nous ne cessons de soupirer de peur qu'il ne s'étaigne (sic) chez nous et pour lequel nous avons toujours été et sommes encore prêts à sacrifier non pas nos biens qui ne sont que par trop médiocres mais nos propres vies $).{ }^{16}$

Le colonel est malheureusement tué peu après dans une expédition sur Détroit, mais il n'aurait pas été plus capable d'aider ses compatriotes que ne le fut le ministre plénipotentiaire La Luzerne auquel les habitants de Vincennes s'adressèrent le 22 aout suivant. ${ }^{17}$

Le pillage continue et les Américains se querellent entre eux. Quand en effet Richard Winston, qui en 1780, a remplacé Todd, accusera de malversations le capitaine Rogers et John Dodge, agent de Jefferson chez les Indiens, il sera simplement arrêté par ses ennemis au mépris de toute légalité et détenu seize jours en prison. C'est alors que la population tout entière se soulève et adresse une pétition au Congrès, qui envoie dans l'Illinois le colonel Harmar. Ce dernier commande tout le nord-ouest et il amène avec lui un marchand français, Barthélémi Tardiveau, qui ne tarde pas à gagner la confiance et des Américains et des Français. Finalement, grâce à ses efforts, le 20 juin 1788, le Comité chargé par le Congrès d'examiner les revendications de l'Illinois proposa que les Français, les Canadiens et autres colons (settlers) sur les terres de l'Illinois qui " avant ou au cours de l'année 1783 s'étaient proclamés citoyens des États-Unis, eussent leurs possessions et leurs titres confirmés et que des dons additionnels de 400 acres fussent accordés à chaque chef de famille ". ${ }^{18} \mathrm{La}$ loi fut promulguée peu de temps après et une autre ajouta un supplément de 100 acres pour tous ceux qui s'étaient enrôlés dans la milice en 1790. Mais il s'éleva au sujet de ces concessions tant de lenteurs que presque tous ceux qui auraient dû en bénéficier durent, poussés par le besoin d'argent, vendre leurs droits à des spéculateurs américains.

Enfin Arthur St. Clair, nommé gouverneur du Nord-Ouest en 1788, arriva le 5 mars 1790 à Kaskaskia, et vers cette date l'ordre fut rétabli tant d'ailleurs du côté religieux que du côté civil. Le 8 juin 1784, la cour de Rome avait issu un décret établissant l'église catho-

16. I.H.C. Vol. II. p. 534-551.

17. I.H.C. Vol. VIII. p. 443.

18. I.H.C. Vol. V. Intro. p. 34. 
lique des Etats-Unis comme un corps indépendant et nommé le révérend John Carroll préfet apostolique. Celui-ci avait alors envoyé dans l'Illinois un carmélite, Paul de St. Pierre, puis un prêtre canadien, Pierre Huet de la Valinière, dont il fit son vicaire-général en 1786. Le choix n'était pas heureux. L'abbé était, suivant l'expression même de l'évêque de Québec, " homme de très bonnes mœurs " mais " d'esprit remuant ").

En fait il se brouilla avec tout le monde, à commencer par l'abbé de St. Pierre et l'abbé Gibault, si bien que ces deux ecclésiastiques finirent par passer sur la rive espagnole entraînant avec eux nombre de leurs paroissiens qui s'établirent dans le futur état de Missouri. Quant à l'abbé de la Valinière, il retourna dans l'état de New York puis au Canada, tandis que l'Illinois était rattaché au diocèse de Baltimore fondé en 1792 .

Ainsi fut réglé le sort de l'ancienne colonie française de l'Illinois qui, toute modeste qu'elle fât, n'en avait pas moins aidé de toutes ses forces et de la façon la plus efficace, la cause de l'indépendance américaine. Car il est indiscutable que l'expédition de Clark et le dévouement des Français aux Américains non seulement assurèrent à ces derniers la possession du Middle-West; mais ils rendirent possibles plus tard et l'acquisition de la Louisiane et la conquête de tous les territoires de l'ouest américain.

\section{Agnès Dukeau}

Western Reserve University, Cleveland, Ohio, E.-U.

Souvenez-vous que la Revue d'Histoire de l'Amérique française vit de ses abonnés et que votre réabonnement devient dû après la réception du présent numéro. 